\title{
The role of early surgery in the treatment of acute diabetic foot in the elderly: a retrospective review
}

\author{
Andrea Bruttocao*, Saverio Spirch, Carmelo Militello, Bruno Martella, \\ Roberto Nistri, Aldo De Rossi, Franco Mazzalai, Silvia Basato, Simone Zanella \\ and Oreste Terranova
}

Address: Clinic of Geriatric Surgery, Hospital University of Padova, Italy

* Corresponding author

from XXI Annual Meeting of The Italian Society of Geriatric Surgery

Terni, Italy. 4-6 December 2008

Published: I April 2009

BMC Geriatrics 2009, 9(Suppl I):A16 doi:10.1 I86/I47I-23I8-9-SI-A16

This abstract is available from: http://www.biomedcentral.com/|47|-23|8/9/SI/A I6

(C) 2009 Bruttocao et al; licensee BioMed Central Ltd.

\section{Clinical background}

In 1996, the overall prevalence of diabetic patients was 120 million and it will more than double by the year 2025.

The most important complication in these patients is the diabetic foot (sepsis, abscess etc.).

The aim of this study was to assess the role and results of surgery, performed in emergency or deferred emergency, in older population affected by acute septic foot.

\section{Materials and methods}

From 01.01.2004 to 01.06.2008, 100 patients (average age $74.5 \pm 7.3$ ) affected by insulin dependent diabetes complicated by sepsis and abscess of the lower limb were treated in emergency surgery.

41 patients were submitted after a visit to immediate surgical drainage and toilets (group A), while 59 patients were transferred from other departments after an average stay of $6.4 \pm 3.2$ days during which only conservative therapy has been implemented (group B).

\section{Results}

No differences were found between the 2 groups regarding age and clinical features (general conditions, concomitant diseases etc.), except for the following differences in Group B: higher levels of glucose in the blood $(\mathrm{P}=0.015)$, lower levels of albumin $(\mathrm{P}=0.005)$, and more frequent extension of inflammatory processes to proximal regions of leg $(P=0.005)$.

The resolution was achieved in group $\mathrm{A}$, without amputation in 9 patients, with amputation of 1 or more toes in 19, with metatarsal amputation in 12 and with Chopart amputation only in 1 case.

Group B: incision and drainage were sufficient only in 4 patients, amputation of 1 or more toes in 21 , minor amputations (metatarsal) in 10, Chopart amputations in 20 patients and mayor amputations (leg) in 4 cases.

The level of amputation was significantly more proximal in group $\mathrm{B}(\mathrm{Chi} 2=24.3 \mathrm{P}<0.001)$.

The logistic regression analysis showed a significant relationship between the level of amputation and the number of days elapsed before debridement (odds ratio, 1.61; P = 0.015 ; confidence interval, 1.10-2.36), but not in presence of peripheral occlusive disease (odds ratio, $1.72, \mathrm{P}=$ 0.376; confidence interval, 0.28-15.2).

\section{Conclusion}

In elderly patient with diabetic, foot the function of lower limbs is significantly reduced in case of delay of surgical debridment for inflammatory process. 